27. Федин А.В. Борьба иезуитов с индейским алкоголизмом в Новой Франции в XVII в. // Вопросы истории. 2016. № 2. С. 68-86.

28. Belmont, abbé. Histoire de l'eau-de-vie en Canada, ca. 1705 // Historical Documents. 1st Series. Vol. 2, No. 8. Quebec, 1840.29 p.

29. Smillie-Adjarkwa C. Aboriginal Alcohol Addiction in Ontario Canada: A Look at the History and Cur- rent Healing Methods That Are Working In Breaking the Cycle of Abuse // Indigenous Policy Journal. Fall 2009. Vol. XX. No. 3. P. 1-9.

30. Denys N. The description and natural history of the coasts of North America (Acadia) / ed. by Ganong W.F. Toronto, Champlain Society, 1908. 657 p.

\title{
ACCULTURATION STRATEGIES: A POLICY OF FRANCIZATION IN A CONTEXT OF JESUIT MISSION IN NEW FRANCE IN FIRST HALF OF THE XVII CENTURY
} (C) 2016

A.V. Fedin, candidate of history sciences, associate professor of General History, International Relations and International Law Department Bryansk State University, Bryansk (Russia)

Abstract. Formation of the difficult and branched out network of the unions with the American Indian tribes, based on mutually advantageous economic and military-political relations was one of the main features of the French colonial regime in Canada of XVII century. As a result, in the first decades of XVII century the most outstanding representatives of secular and spiritual colonisation of New France (Champlain, Recollects and Jesuits) started working out the most effective strategy of Franco-Amerindian rapprochement and the cooperation, embodied in the program «francization», i.e., ideas of acculturation and assimilation of the native population of Canada by Frenchmen as basic means of social and economic and political development of a colony. Catholic missionaries including members of a Jesuit order were interested in realisation of this program at the initial stage of development of new territories and formation of a colonial infrastructure, as material basis of their apostolate activity among the American Indian peoples. From this point of view, «Civilisation» of Indians on the French sample was considered priority in relation to Christianization. In the process of Jesuit mission network expansion among the cores of trading and military colony partners and the Jesuit missionary transformation into the main intermediary in Franco-Amerindian relations in the middle of XVII century, on the one hand, and growth of contradictions with the secular colonial power on a wide spectrum of problems (including trade in alcoholic drinks), Jesuits began to audit initial positions of the «francization» program, resulted in 2 nd half of the century to full refusal of them and the statement of a primacy of the religious reference over the cultural.

Keywords: Catholic church; Jesuits; missionary activity; New France; Quebec; Acadie; North American Indians; Algonquins; Hurons; Iroquois; assimilation; acculturation; accommodation; francization; colonisation; alcoholism; epidemics; fur-trade; reductions.

УДК 94(470.66)Т-50

\section{БЕЙ-БУЛАТ ТАЙМИЕВ - ВЫДАЮЩИЙСЯ ВОЕННО-ПОЛИТИЧЕСКИЙ ДЕЯТЕЛЬ ЧЕЧНИ ПЕРВОЙ ТРЕТИ ХІХ ВЕКА}

(C) 2016

\section{P.A. Товсултанов, кандидат исторических наук, доцент кафедры новой и новейшей истории Чеченский государственный университет, Грозный (Россия)}

Л.Н. Галимова, доктор исторических наук, профессор кафедры гуманитарных и социальных дисциплин Ульяновский институт гражданской авиации имени главного маршала авиации Б.П. Бугаева, Ульяновск (Россия)

Аннотащия. В настоящей статье проведен анализ военно-политической обстановки в Чечне, сложившейся в конце XVIII - первой четверти XIX вв. Отмечается, что кризис военно-политической обстановки в Чечне происходит после того, как в начале XIX века к России был присоединен ряд областей и государств Закавказья. Теперь установление эффективного контроля над непокоренными горцами превращается для царизма из задачи сугубо пограничной в задачу стратегическую. Выполнение ее было поручено генералу А.П. Ермолову, который все свое внимание обращает на Левый фланг (куда входила и Чечня) Кавказской линии. И с этого времени приоритетным направлением в его действиях становится Чечня. Ермолов сразу же стал проводить жесткую политику по отношению к горцам, частыми становятся карательные экспедиции с целью устрашения чеченцев. Такая политика А.П. Ермолова постепенно привела к консолидации различных чеченских обществ, прежде разделенных на кланы и племена. Доведенные до отчаяния жесткой политикой кавказского наместника чеченцы в 1825 г. поднимают восстание. Возглавил объединительное движение Бей-Булат Таймиев. В статье исследуется восстание Бей-Булата Таймиева в 1825-1826 гг., отмечаются причины и характер движения горцев, проанализированы причины поражения и итог восстания. Оцениваются роль и значение Бей-Булата Таймиева в истории Чечни.

Ключевые слова: Чечня; царизм; военно-политическая обстановка; царская администрация; восстание; горцы; политика России; сопротивление; восставшие; царские войска; военный поход; движение горцев; Дагестан; Кавказ; непокорные горцы; консолидация; уничтожение; наместник; царская власть; всеобщее восстание; Северный Кавказ; чеченцы; репрессивная политика. 
В 1820-х годах, еще до появления в Дагестане Гази-Мухаммеда и Гамзат-бека, народно-освободительную борьбу чеченского народа возглавил выдающийся политический деятель Чечни Бей-Булат Таймиев. Он был выходцем из простого народа, старшиной, военно-политическим руководителем в Чечне. Его поддерживала большая часть чеченцев. Бей-Булат Таймиев родился в 1779 году в селении Бильтой. Он обладал незаурядным политическим чутьем, был хорошо осведомлен о характере действий царизма на Кавказе, умел налаживать нужные отношения с властями [1, c. 3, 5].

В российских источниках Бей-Булат впервые упоминается в связи с событиями 1802 г., когда он с группой горцев совершил за Тереком нападение на казачий патруль.

После этого случая имя Бей-Булата Таймиева все чаще звучит в рапортах военного командования Левого фланга Кавказской линии. Он постепенно превращается в одного из самых влиятельных чеченских старшин. Увидев, что авторитет Бей-Булата быстро растет, царское командование на Кавказе посчитало необходимым привлечь его на свою сторону. Вскоре, в сентябре 1807 г., он получает от русских властей чин подпоручика с соответствующим жалованьем. Свой очередной чин поручика Таймиев получил при Ермолове, в 1816 г.

Принятие на службу не обязывало его к какой-то постоянной деятельности, и он мог «спокойно жить у себя на родине, т.е. Гельдигене». Это было что-то вроде контракта, по которому Таймиев, со своей стороны, пообещал воздержаться от совершения рейдов на казачьи поселения по Тереку [2, с. 53-54].

После того как к России в начале XIX века был присоединен ряд областей и государств Закавказья, установление действенного контроля над непокоренными горцами превращается для царизма из задачи сугубо пограничной в задачу стратегическую. Выполнение ее было возложено на генерала А.П. Ермолова, в 1816 году назначенного командиром Отдельного кавказского корпуса [3, с. 99]. Прибыв на Кавказ, Ермолов решил сконцентрировать все свое внимание на Левом (восточном) фланге Кавказской линии. В этом плане он придавал первостепенное значение положению дел в Чечне - житнице Дагестана [3, с. 99]. Вскоpe, 18 мая 1818 г., на р. Сунжа Ермолов начал строительство крепости Грозная. Так Ермолов сделал первый шаг в долгой колонизации, решение о которой приняла царская власть $[4$, с. 54-55]. И с этого времени «...жесткая и целенаправленная политика А.П. Ермолова приводит к прямым военным столкновениям дагестанских и чеченских отрядов с царскими войсками и почти ежегодным карательным экспедициям для усмирения непокорных» [5, с. 151].

Ермолов, не откладывая дело, стал проводить жестокую политику по отношению к горцам, частыми становятся теперь карательные экспедиции с целью устрашения чеченцев. В сентябре 1819 г., с целью напугать непокорных горцев, Ермолов безосновательно уничтожил чеченское село Дады-Юрт вместе с его населением, что является одной из самых трагических страниц в истории Кавказской войны. Ермолов в какой-то степени достиг своего: уничтожение ДадыЮрта поистине было «примером ужаса». Даже От- дельные исследователи XIX в. даже назовут это «резней» $[6$, с. 254, 247]. Такая политика А.П. Ермолова постепенно привела к консолидации различных чеченских обществ, прежде разделенных на кланы и племена. Возглавил объединительное движение БейБулат Таймиев [7, с. 28]. По мнению М.М. Блиева и В.В. Дегоева, экспедиция генерала Грекова в феврале 1822 г., во время которой царская армия уничтожила крупное селение Шали, послужила тем завершающим звеном, которого не доставало в процессе консолидации чеченского общества перед лицом военноэкономической блокады А.П. Ермолова [8, с. 222]. «Первый взрыв организованного всеобщего возмущения произошел в 1822 г. Это сопротивление, направленное «на защиту своей земли и самостоятельности, против насаждения царской администрации и колониальных порядков», носило "освободительный характер"» [9, с. 135]. Из-за плохой организованности это восстание к концу года было подавлено [10, с. 57].

Однако доведенные до отчаяния жесткой политикой кавказского наместника А.П. Ермолова чеченцы в 1825 г. поднимают новое восстание. Движение, подавленное в 1822 г., с весны 1825 г. набирает новую силу [8, с. 229, 234]. 29 мая 1825 г. в Майртупе состоялся съезд старшин, на котором майртупский мулла Магома (Магомед Майртупский) был провозглашен имамом. Фактическим руководителям восстания стал Бей-Булат Таймиев, что подчеркивает светский характер восстания. Хотя руководителем восстания был избран религиозный человек, авторитет Бей-Булата, человека светских взглядов, был выше. Духовенство в восстании играло подчиненную роль. Восставшие требовали возвращения им земель, отнятых у них при строительстве крепости Грозная и укреплений по p. Сунжа [11, с. 117]. Восстание охватило не только Чечню, но и Кумыкскую плоскость.

Надо сказать, что Бей-Булата Таймиева в то время хорошо знали не только на Кавказе, но и в высших кругах Петербурга и за пределами России. Он неоднократно делает попытки завязать отношения с Дагестаном (из Дагестана в Чечню прибыли свыше 300 лезгин во главе с гумбетовским кадием Дабир-Али и аварским чанкою Андаловым [12]), Кабардой и Грузией. С этой целью даже ездил в Иран. Видимо, он понимал, что противостоять в одиночку армии, одной из самых сильных в Европе, которая к тому времени приобрела огромный опыт ведения военных действий в войнах с Францией, Турцией и Ираном, невозможно [13]. Восстание было настолько мощным, что некоторые авторы (Р. Магомедов [14], Фадеев А.В. [15]) полагали, что весной в 1825 г. в Чечне были провозглашены газават и джихад.

Открытое вооруженное выступление против царских властей Б. Таймиев начинает в июне 1825 года, осадив крепость Герзель-аул. После двухнедельной осады он оставляет эту крепость и переносит действия на кумыкскую плоскость, где штурмом захватывает укрепление Амир-Аджи-Юрта, затем - Злобный окоп и крепость Преградный Стан. В середине июня Б. Таймиев снова осаждает Герзель-аул. Командовавший царскими войсками генерал Греков выставил против восставших 3360 человек с орудиями. С ним выступил и генерал О.Т. Лисаневич. В результате восставшие были вынуждены отступить [16, с. 62]. 
Товсултанов Р.А., Галимова Л.Н.

На следующий день, 16 июля, Лисаневич решил собрать в Герзель-аульском укреплении аксаевских старшин. В укрепление было приглашено 318 человек. Когда Лисаневич попытался их разоружить и арестовать, несмотря на обещанную безопасность, чеченский старшина Учар-Хаджи сначала нанес смертельный удар кинжалом Грекову, затем смертельно ранил Лисаневича [1, с. 77]. Это событие способствовало всеобщему восстанию кумыков. Однако в июле 1825 г. в среде восставших намечается раскол. На совещании руководителей движения в Аксае «влиятельные муллы» (очевидно, чеченцы) отказали Бей-Булату в дальнейшей поддержке. Это обстоятельство показывает, что уже в середине 1825 г. в движении появляется трещина - аульская верхушка начинает отходить от восстания [17, с. 144-145]. Тем не менее БейБулат не прекратил борьбу. Он собрал новых борцов, и это новая двухтысячная повстанческая армия направилась к Шали, Хан-Кале, в Малую Чечню, к Гойте и к селу Гехи. Командованию Левого фланга, потерпевшему поражение в этой борьбе, оставалось находиться в роли наблюдателей, так как силы его были истощены [1, с. 79]. Восстание приняло такой угрожающий характер, что больной Ермолов из Тбилиси поспешно выехал в Чечню. Здесь он мобилизовал все войска, находившиеся на линии, и с этими войсками лично отправился в очаги восстания. Ермолов жестоко расправлялся с восставшими. На месте полуразрушенных укреплений он стал возводить новые, вселяя в них большой количество войск [18, c. 35].

29 августа Бей-Булат с 60 всадниками совершает нападение на крепость Грозный, однако, не сумев овладеть этой крепостью, он без ощутимых потерь возвращается в Ханкальское ущелье. По мнению М. Вачагаева, этот акт был совершен в целях пропаганды. Взятие самой важной крепости на Северном Кавказе должно было вдохновить чеченцев и показать им возможность победы над царскими войсками, несмотря на малочисленность и слабое вооружение [2, с. 70]. Ермолов, выступив из крепости Грозный 26 января и преследуя Бей-Булата с отрядом в 4 с половиной батальона, с 600 казаками и с 15 орудиями, достигает аула Атаги. Через день царские войска без боя, как отмечают некоторые исследователи, заняли Атаги, в спешке покинутое жителями. Однако участник тех событий, артиллерийский офицер Э.В. Бриммер, отмечает совсем другое: «Часа в четыре... мы пришли к огромному аулу Большой Атаги, где чеченцы собрались, чтобы защищаться. ...Рукопашный бой был ужасный, ибо огромный аул был полон - семейства не вывезены, все имущество и скот оставались дома. Когда солдаты врывались в дома за убегавшими чеченцами, женщины встречали их с кинжалами в руках, яростно бросались на них и погибали на штыках». 30 января Ермолов направил крупный отряд (2 батальона, 1 рота, 500 казаков и 6 орудий) для захвата селения Чахкери, где находились основные силы восставших. Само селение было занято без боя и «превращено в пепел». Повстанцы, главным образом чахкеринцы и атагинцы, напали на российский отряд, когда он уже возвращался в Атаги. «Кровопролитие бы- ло ужасное, - писал об этом бое П. Зубов. - Все офицеры наши, находившиеся в стрелках, лично участвовали в рукопашном бое, завязавшемся на всей линии...». Кровавые жертвы «не останавливали, однако же, чеченцев, находившихся в религиозном экстазе; они прорвались за цепь, и батальонам пришлось вступить в штыковую схватку, - отмечал В.А. Потто. Сами чеченцы говорили потом, что не помнят такой ожесточенной свалки». Обе стороны дрались с одинаковым ожесточением, но исход боя решило преимущество регулярной армии и артиллерия. Э.В. Бриммер, участвовавший и в чахкеринском бою, писал, что здесь было ранено свыше 300 российских солдат и офицеров и несколько десятков было убито. После поражения под Чахкери повстанческие силы рассеялись, и Ермолов со своим отрядом вернулся в Грозный [9, с. 160, 161, 162].

Необходимо отметить, что в последние годы своего пребывания на Кавказе А.П. Ермолов понял, что жесткой и репрессивной политикой погасить пламя борьбы горцев не удастся. И тогда он 20 февраля 1826 года, составил и разослал по чеченским деревням «Прокламацию». По сравнению с ранними «Прокламациями» от 1818 г. (т.е. начального периода его правления) «Прокламация» 1826 года имела более умеренный тон, в ней существенно меньше надменновысокомерной, жестокой неумолимости; отсутствовали угрозы: «...село будет сожжено». В ней также отсутствовали многие жесткие требования об ответственности всего села за действия отдельных «удальцов», о поголовном и обязательном участии всего населения в борьбе с чеченскими партиями, прорывавшимися к Линии и т.д. Возможно, что Ермолов, прослужив на Кавказе 10 лет, понял тщетность усилий покорить чеченцев только силой и многому сам научился. Недооценить этот документ нельзя, так как он показывает, что политика царской администрации в крае начинает меняться. Можно сказать, что в политике царизма по отношению к чеченскому народу курс как бы менялся от жесткого и бескомпромиссного к более или менее либеральному. Движение горцев начинает ослабевать [1, с. 96, 97].

Таким образом, в результате военных походов Ермолова весной 1826 г. и благодаря его умеренной политике в крае, сопротивление чеченцев царским войскам начинает ослабевать, и в мае восстание было подавлено.

Итак, подводя итог, отметим, что восстание $1825-$ 1826 гг., являвшееся, по мнению Р. Магомедова, одним «из самых крупных» и явившееся «следствием ермоловской политики» [18, с. 34], почти не имевшее религиозной окраски, несмотря на определенные успехи на начальном этапе, потерпело неудачу [19, c. 17]. К концу весны 1826 г., из-за несоразмерности сил, отсутствия единой централизованной власти, недостаточности координации с другими народами Северного Кавказа и частого разлада в руководстве движения, восстание это было подавлено царскими войсками [2, с. 80].

По словам Н.И. Покровского, «восстанием БейБулата заканчивается подготовка мюридизма. Здесь борьба переходит уже в формы массовых восстаний, 
хотя и не имеющих пока яркой религиозной окраски... Восстание Бей-Булата уже слегка окрашено мусульманством, но последнее является и здесь моментом не основным» [17, с. 147].

Ермолов в последние годы своего пребывания на Кавказе приходит к выводу, что одних силовых мер недостаточно для превращения чеченцев в покорных подданных Российского государства (именно восстание в Чечне в 1825-1826 гг. под руководством БейБулата Таймиева заставили Ермолова пересмотреть свою систему взглядов на методы и средства установления российской власти в Чечне [20, с. 22]). Нужны еще, и прежде всего, меры экономические, политические и административные. В мае 1826 г. он отмечает: «...Временного наказания недостаточно для людей, обвыкших к безначалию, к свободе буйной и не обузданной и ...необходимы постоянные меры». Тогда же он направил предписание новому начальнику Левого фланга генерал-майору Лаптеву, которое должно было стать программой действий российских властей в отношении Чечни. В нем главнокомандующий отметил: «...Нужным нахожу обратить в особенности внимание на чеченцев». «Никогда не требуйте того, что для них исполнить трудно или чего они вовсе исполнить не могут, ибо за ослушанием должно следовать наказание». Впервые Ермолов указывает, что «надобно стараться сблизить чеченцев частым их обращением с русскими», для чего необходимо, прежде всего, развитие торгово-экономических связей между ними (раньше Ермолов был сторонником военноэкономической блокады). Для эффективного развития торгово-экономических связей между горцами и русскими в Грозном был учрежден меновой двор, что явилось важным шагом вперед в развитии этих связей [6, с. 331,332$]$.

В связи с отъездом генерал-майора Лаптева на иранский фронт, в августе 1826 г. по распоряжению Ермолова на должность командира Левого фланга назначается Евстафий Федорович Энгельгардт, который пробыл на этом посту до февраля 1830 года. Энгельгардту в какой-то мере удалось усилить пророссийскую ориентацию горцев.

Энгельгардт был человеком мыслящим, начитанным, инициативным и гуманным. В Чечне он пытался проводить более умеренную и гибкую политику. В годы его начальствования партия сторонников пророссийской ориентации, отражавшая настроения трудовой Чечни, укрепила свои позиции. Видимо, горцам надоела жизнь, протекавшая в обстановке постоянной военной тревоги [1, с. 113].

Е.Ф. Энгельгардт начал свою деятельность в Чечне с августа 1826 г. С самого начала он стал тщательно изучать военно-политическую и общественно-экономическую обстановку на месте. Его интересовало все: обычаи чеченцев, состав влиятельных лиц, их отношения к частной собственности, царским властям, к религии, к зарождающемуся мюридизму, к торговле, различия между горной и равниной Чечней. И уже через год и четыре месяца он разработал проект положения для управления чеченцами и подал его командующему линией генералу Емануелю. Им также была составлена и «Новая конституция для чеченского пристава», которым тогда стал Золотарев. Пока его проекты отлеживались в вышестоящих канцеляриях, они становились известными в Чечне. Отсюда и поддержка Энгельгардта частью чеченцев. Именно в этот период (1826-1827 гг.) видя, что политическая обстановка в Чечне начала меняться в лучшую сторону, Бей-Булат начал менять направление своей политики, постепенно разрывая временный союз с Нох-ханом (лидер антироссийской феодальной оппозиции в Дагестане - Р.Т.). По мнению Л.Н. Колосова, политический курс, избранный Энгельгардтом в Чечне, подрывал влияние Бей-Булата на чеченцев [1, с. 114].

В 1829 г. чеченцы в «Прошении Паскевичу» писали, что от начальника Левого фланга генерала Энгельгардта «мы приобрели спокойствие и для подданных Его Императорского Величества не видим со стороны его лжи, обмана и нарушение условий» и «...не делается от него народу никакой обиды и несправедливости во время суда, что самое умножило между нами любовь и расположение. Прекратились у нас все несправедливости и вражды, распространились между всеми нашими народами в горах и на плоскости живущими повиновение и покорность к вышеозначенному генералу, и никого нет неповинующегося ему, кроме небольшой части» [21, с. 913]. Из «Прошения» видно, что даже в горных районах Чечни, которые раньше слабо шли на мирные контакты, усилилась пророссийская ориентация. Это лишний раз доказывает тезис о том, что добро порождает добpo, а зло порождает зло. Раньше, когда в царской политике в Чечне преобладали жесткость и насилие, ответные действия горцев были такими же, а теперь, благодаря политике, проводимой Энгельгардтом, отношения между царскими властями и чеченцами стали вполне мирными. Именно эти отношения не позволили Бей-Булату в 1826-1828 гг. поднять горцев на антироссийское восстание.

Безусловно, политика Энгельгардта в Чечне была близка простому чеченскому народу, она отвечала его требованиям, чеченцы охотно шли на диалог с начальником фланга. Эта политика принесла определенные успехи в российско-чеченских взаимоотношениях. В этот период (конец 20-х - начало 30-х гг. XIX вв.) развивались преимущественно мирные отношения - это особенный этап в российско-чеченских отношениях. Впервые царская власть попыталась найти компромисс с чеченцами, прислушаться к их мнению о принципах и условиях присоединения Чечни к России, в частности о прекращении военных экспедиций царских войск против чеченцев. Подобная политика царских властей встретила со стороны чеченцев полное понимание, теперь они стремились мирным путем решить имеющиеся разногласия в российско-чеченских взаимоотношениях. Чеченцы готовы были принять российское подданство при сохранении их внутреннего самоуправления, т.е. при условии неприкосновенности их земли, обычаев, традиций и религии. Это был самый эффективный и перспективный путь для развития российско-чеченских взаимоотношений. Если бы намеченная тенденция в царской политике в крае была бы продолжена, может быть, и удалось бы избежать кровавой многолетней Кавказской войны [6, с. 366, 367]. 
Товсултанов Р.А., Галимова Л.Н.

Увы, «бархатный» [6, с. 367] период в российскочеченских взаимоотношениях был недолгим. Его главные проводники вскоре ушли с Кавказа. Энгельгардт в 1830 г. был возвращен в Кисловодск. Главнокомандующий в Грузии в $1827-1831$ гг. граф И.Ф. Паскевич был отправлен в Польшу, в том же году был убит политический лидер чеченцев Бей-Булат. У нового наместника Г.В. Розена были свои представления о том, какой должна быть политика по отношению к горцам. Отказавшись от политики своего предшественника, он предпочел военные, силовые методы в разрешении «горского вопроса».

Таким образом, из всего вышесказанного можно сделать вывод, что Бей-Булат Таймиев был сыном своего времени. Он был народный вождь, завоевавший своими действиями авторитет и уважение не только чеченского народа, но и многих других народов Кавказа. Первую треть XIX века в истории Кавказа без преувеличения можно называть «эпохой БейБулата». Его борьбе за свободу и независимость горцев сочувствовали А.С. Пушкин, А.С. Грибоедов, а затем - М.Ю. Лермонтов, Л.Н. Толстой.

\section{СПИСОК ЛИТЕРАТУРЫ:}

1. Колосов Л.Н. Славный Бейбулат. Грозный, 1991. $173 \mathrm{c}$

2. Вачагаев М. Чечня в Кавказской войне XIX ст.: события и судьбы. Киев, 2003. 368 с.

3. Кудрявцев А. Чеченцы в восстаниях и войнах XVIII-XIX веков // Вестник Евразии. № 1. М., 1996. C. $95-110$.

4. История горских народов Кавказа. Нальчик, 2004. $120 \mathrm{c}$

5. Патракова В.Ф. Освободительная борьба народов Северного Кавказа (1818-1864 гг.) // Ученые записки. Т. 14. Ростов-на-Дону, 2000.
6. Гапуров Ш.А., Абдурахманов Д.Б. Россия и Чечня (последняя треть XVIII - первая половина XIX века). Грозный, 2009. 522 с.

7. Данлоп Д. Россия и Чечня: история противоборства. Корни сепаратистского конфликта. М., 2001. $231 \mathrm{c}$.

8. Блиев М.М., Дегоев В.В. Кавказская война. М., 1994. $592 \mathrm{c}$.

9. История Чечни с древнейших времен до наших дней. Т. ІІІ. Грозный, 2013. 656 с.

10. Товсултанов Р.А. Социально-политическое развитие Чечни в конце 20-х - 50-х гг. ХІХ века: дис. ... канд. ист. наук. Грозный, 2013. 217 с.

11. Северный Кавказ в составе Российской империи. М., 2007. 460 c.

12. РГВИА. Ф. 482. Оп. 1. Д. 123. Л. 20.

13. Исаев С-А.А. Из истории присоединения Чечни к России // Чеченцы в сообществе народов России. T. 2. Назрань, 2008. С. 33-41.

14. Магомедов Р. Борьба горцев за независимость под руководством Шамиля. Махачкала, 1991. С. 35.

15. Фадеев А.В. Возникновение мюридистского движения на Кавказе и его социальные корни // История СССР. 1960. № 4. С. 53.

16. Вачагаев М. Гроза Кавказа // Дош 3 (33) / 2011. C. $59-64$.

17. Покровский Н.И. Кавказские войны и имамат Шамиля. М., 2000. 511 с.

18. Магомедов Р. Борьба горцев за независимость под руководством Шамиля. Махачкала, 1939.

19. Товсултанов Р.А. Социально-политическое развитие Чечни в конце $20-\mathrm{x}-50-\mathrm{x}$ гг. ХІХ века. автореф. ... канд. ист. наук. Владикавказ, 2013. 30 с.

20. Гапуров Ш.А. Чечня и Ермолов $(1816-$ 1827 гг.). Грозный: ГУП «Книжное издательство», 2006. $516 \mathrm{c}$.

21. АКАК. VII. Тифлис, 1878.1011 с.

\section{BEY-BULAT TAYMIEV AS AN OUTSTANDING MILITARY AND POLITICAL FIGURE OF CHECHNYA IN THE FIRST QUARTER OF THE XIX CENTURY}

R.A. Tovsultanov, candidate of history sciences, associate professor of Modern and Contemporary History Department Chechen State University, Grozny (Russia)

L.N. Galimova, doctor of history sciences, associate professor, professor of Humanities and Social Sciences Department

Ulyanovsk Institute of Civil Aviation named after chief Marshal of aviation B.P. Bugaev, Ulyanovsk (Russia)

Abstract. This paper analyzes the political and military situation prevailing in Chechnya at the end of XVIII - the first quarter of the XIX century. The authors note that the crisis of the military-political situation in Chechnya occurred after a number of regions and countries of the Caucasus joined Russia in the early XIX century. The establishment of effective control over the unconquered mountain people converted from a purely «border» problem into a strategic task for the tsarism. This task was given to General A.P. Yermolov who paid all his attention to the left wing (which included Chechnya) of the Caucasian line and Chechnya became a priority of his policy. A.P. Yermolov immediately began to carry out a rigid policy towards the mountaineers, the aim of frequent punitive expeditions was to intimidate the Chechens. A.P. Yermolov's policy gradually led to the consolidation of different Chechen communities, primarily divided into clans and tribes. This rigid policy of the Caucasian Chechen governor in 1825 raised uprising. Bay-Bulat Taymiev headed this movement. In this connection the paper also explores the uprising of Bay-Bulat Taymiev in 1825-1826, the causes and nature of the movement of mountaineers, analyzes the causes of the defeat and the result of the uprising. The authors assess the role and significance of Bay-Bulat Taymiev in the history of Chechnya.

Keywords: Chechen Republic; tsarism; military-political situation; tsar's administration; revolt; highlanders; politics of Russia; resistance; insurgent; tsar's troops; military hike; motion of highlanders; Dagestan; Caucasus; rebellious highlanders; consolidation; elimination; deputy; tsar's power; universal revolt; North Caucasus; Chechens; repressive politics. 